\title{
Managing Expectations of Antibiotics for Upper Respira- tory Tract Infections: A Qualitative Study
}

\author{
Mobammed Mustafa, BSc Hons, \\ $M B C b B, M R C G P, M S c^{1}$ \\ Fiona Wood, MSc, $P b D^{1}$ \\ Christopher C. Butler, MBCbB, \\ DCH, FRCGP, CCH, MD, FFPH
}

Glyn Elwyn, MBCbB, MSc, FRCGP, $\mathrm{PbD}{ }^{2}$

${ }^{1}$ Cochrane Institute of Primary Care and Public Health, Cardiff University School of Medicine, Cardiff, United Kingdom

${ }^{2}$ Dartmouth Center for Health Care Delivery Science, Dartmouth College, Hanover, New Hampshire
AC Annals Journal Club selection; see inside back cover or www.annfammed. org/AJC/.

Conflicts of interest: authors report none.

\section{CORRESPONDING AUTHOR}

Mohammed Mustafa, MBChB, MRCGP, MSc Cochrane Institute of Primary Care and Public Health

Cardiff University School of Medicine

Neuadd Meirionnydd, Heath Park

Cardiff, CF14 4YS

United Kingdom

mustafamh@cardiff.ac.uk

\begin{abstract}
PURPOSE Communication experts have suggested that it is good practice to ask patients' directly whether they expect to receive antibiotics as part of asking about the triad of ideas, concerns, and expectations for health care. Our aim was to explore the views and experiences of family physicians about using this strategy with their patients, focusing the interview on the problem of eliciting expectations of antibiotics as a possible treatment for upper respiratory tract infections.
\end{abstract}

METHODS We conducted a qualitative study using semistructured interviews with 20 family physicians in South Wales, United Kingdom, and performing thematic analysis.

RESULTS Family physicians assumed most patients or parents wanted antibiotics, as well as wanting to be "checked out" to make sure the illness was "nothing serious." Physicians said they did not ask direct questions about expectations, as that might lead to confrontation. They preferred to elicit expectations for antibiotics in an indirect manner, before performing a physical examination. The majority described reporting their findings of the examination as a "running commentary" so as to influence expectations and help avoid generating resistance to a soon-tobe-made-explicit plan not to prescribe antibiotics. The physicians used the running commentary to preserve and enhance the physician-patient relationship.

CONCLUSIONS Real-world family physicians use indirect methods to explore expectations for treatment and, on the basis of their physical examination, build an argument for reassuring the patient or parent. In contrast to proposed models in the communication literature, interventions to promote appropriate antibiotic prescribing might include a focus on training in communication skills that (1) integrates these indirect methods as part of building collaborative physicianpatient relationships and (2) uses the running commentary of examination findings to facilitate participation in clinical decisions.

Ann Fam Med 2014;29-36. doi:10.1370/afm.1583.

\section{INTRODUCTION}

I $\mathrm{n}$ an attempt to achieve more appropriate prescribing of antibiotics for self-limiting conditions such as acute upper respiratory tract infections (URTIs), many communication experts suggest that physicians directly determine whether patients, or parents, expect to receive antibiotics. ${ }^{1-5}$ These suggestions have emerged from studies on how best to conduct consultations when antibiotics are deemed clinically inappropriate, but are nevertheless prescribed because of patient or parent expectations for antibiotics, as perceived by their physician. ${ }^{3,6,7}$

Researchers have found that physicians rarely seek patient expectations, and by failing to do so, their perceptions of patient expectations can be unreliable and may indeed overestimate actual patient demand. 2,3,7,8 Various interventions seeking to facilitate the direct elicitation, and also the shaping, of patient expectations have been developed and evaluated. They include communication skills training, the possible use of running commentaries to convey the findings during physical examination, and the use of patient information leaflets or other forms of decision support. ${ }^{4,5,-18}$ 
Little attention has been paid to asking family physicians how and why they practice the way they do in handling expectations for antibiotics in URTI consultations, however. Furthermore, any recommendations for particular approaches would be more feasible if actually grounded in the experiences of physicians working in everyday family medicine. This qualitative study therefore set out to explore how and why family physicians elicit and address patients' or parents' expectations for antibiotics.

\section{METHODS}

\section{Study Design}

We chose to use qualitative research methods because we wanted to explore in depth the perspectives of family physicians from their own point of view, rather than quantify preexisting categories that we already knew about.

We conducted in-depth, semistructured interviews with 20 family physicians in South Wales (United Kingdom). Signed informed consent was obtained from all the participants before the interviews. We also obtained research ethics committee and local research governance approvals (Multi Research Ethics Committee for Wales, reference number 10/WMW02/24).

\section{Sampling and Recruitment Procedures}

A database of family physicians in the Cardiff and Vale University Health Board was generated from the Health Boards publicly accessible website. Family physicians were invited to participate by letter and were provided information about the study. Once the physician had confirmed interest, by way of a reply slip, the primary author (M.M., an academic family physician) telephoned to discuss the study further, answer any related questions, and arrange a time for the interview.

\section{Data Collection}

The primary author conducted a single faceto-face interview with each of the 20 participants between October 2010 and April 2011. Each interview was digitally recorded with the consent of the participant. Participants were assured anonymity. A review of the academic and policy literature was used to develop a semistructured interview schedule that included open questions about general opinions on the URTI consultation (Table 1). We took care to ensure that the interview schedule did not constrain discussions and adapted it to allow further discussion of points introduced by the participant. To cre- ate an open and comfortable atmosphere, each interview began with confirmation that it was not a test of knowledge or an audit to assess whether they were adherent to the latest guidelines. Participants were given the option of receiving a copy of the transcript to verify accuracy and offer comments (ie, a member check $^{19}$ ), although none took up this opportunity.

\section{Data Analysis}

Each interview was transcribed and any identifying data were removed. Data were analyzed using thematic analysis after completion of data collection. ${ }^{20}$ Initially, this approach meant that a proportion of transcribed interviews (25\%) were independently coded by 2 of the authors (M.M. and G.E.). Line-byline reading of the transcripts led to identification and annotation of numerous interpretations. These interpretations were then given codes. After performing independent coding, we conducted comparative coding that involved discussion of the codes and how they were developed. Differences among the researchers were resolved by returning to the transcripts to check meaning and reach a consensus. We continuously compared emerging codes between transcripts. Data were tabulated according to codes (Table 2). After the coding of 17 interviews, 1 author (M.M.) assessed the data for theoretical saturation by reviewing the codebook (the working document that records updates in changes to codes) and concluded that no new themes were emerging from the data ${ }_{i}$ however, we decided to continue interviewing an additional 3 participants to ensure full saturation.

\section{Table 1. Interview Guide}

\begin{tabular}{|c|c|}
\hline Main Topic Area & Specific Approach \\
\hline Introductions & Explain rationale for the study \\
\hline \multirow[t]{6}{*}{ URTI consultation } & Inquire how they manage the URTI consultation \\
\hline & $\begin{array}{l}\text { Interviewer to use open questions until satisfied partici- } \\
\text { pants' comments highlight: }\end{array}$ \\
\hline & Usual practice \\
\hline & $\begin{array}{l}\text { An understanding as to why, how, and when they } \\
\text { elicit expectations, if at all }\end{array}$ \\
\hline & The type of gambits used and why they use them \\
\hline & How they structure their consultation \\
\hline Eliciting expectations & $\begin{array}{l}\text { Ask for their views on eliciting expectations for } \\
\text { antibiotics }\end{array}$ \\
\hline \multirow[t]{5}{*}{ Consultation map } & $\begin{array}{l}\text { Show participants a visual aid of the consultation map } \\
\text { and seek participants' views on whether it is a valid } \\
\text { representation: }\end{array}$ \\
\hline & Gathering information 1: history \\
\hline & Gathering information 2: examination \pm commentary \\
\hline & Diagnosis spin \\
\hline & Management plan \pm negotiating shared decision \\
\hline \multirow[t]{2}{*}{ Wrap-up } & Ask if there are any questions \\
\hline & Ask whether this has been an opportunity to reflect \\
\hline
\end{tabular}


The next level of analysis involved identifying relationships between the codes and grouping them into coherent concepts. The final level of analysis grouped the concepts into major categories. Differences among the researchers were resolved by returning to the transcripts, codes, and/or higher-level analysis to reach a consensus. Throughout, we remained conscious of the need to be reflexive and aware of our own backgrounds and experiences, to avoid unduly influencing the participants' views or our interpretation of the data.

\section{RESULTS}

We invited 218 family physicians in 55 practices in Cardiff by letter. Ten responded to declare an interest in participating in the study. Two family physicians provided names of 3 of their colleagues who were interested in being interviewed but had not responded to the written invitation. The primary author contacted the nonresponders by telephone, e-mail, or both until an additional 7 family physicians had been recruited.

Of the 20 family physicians who participated, 13 $(65 \%)$ were male, $16(80 \%)$ had held their primary medical degree for at least 10 years, 17 (85\%) had qualified as a physician in the United Kingdom, and 17 (85\%) held UK Membership in the Royal College of General Practitioners (MRCGP) or higher. The interviews lasted an average of 29 minutes (range, 20-53 minutes). By comparison, of those who had not responded and for whom data were available, 90\% (126 of 140) had at least 10 years of experience.

The themes we identified from the interviews are detailed in Table 2 and summarized in Table 3.

\section{Views on Managing the URTI Consultation: The Challenges}

Many of the family physicians described the URTI consultation as a source of potential conflict. As one shared, "Slight sort of anticipation of confrontation, because, you know, most of the time patients can heal themselves, and you gotta' persuade them of that. So, little bit of apprehension as to how they're going to take that" (family physician [FP]17).

The degree of challenge appeared proportional to what family physicians perceived to be the patients' desire for antibiotics. As one physician noted, "The only thing that makes it difficult is the patient's expectation" (FP20). And another said, "It's always tricky

\section{Table 2. Themes, Subthemes, and Codes Describing Family Physicians' Views and Experiences of the URTI Consultation}

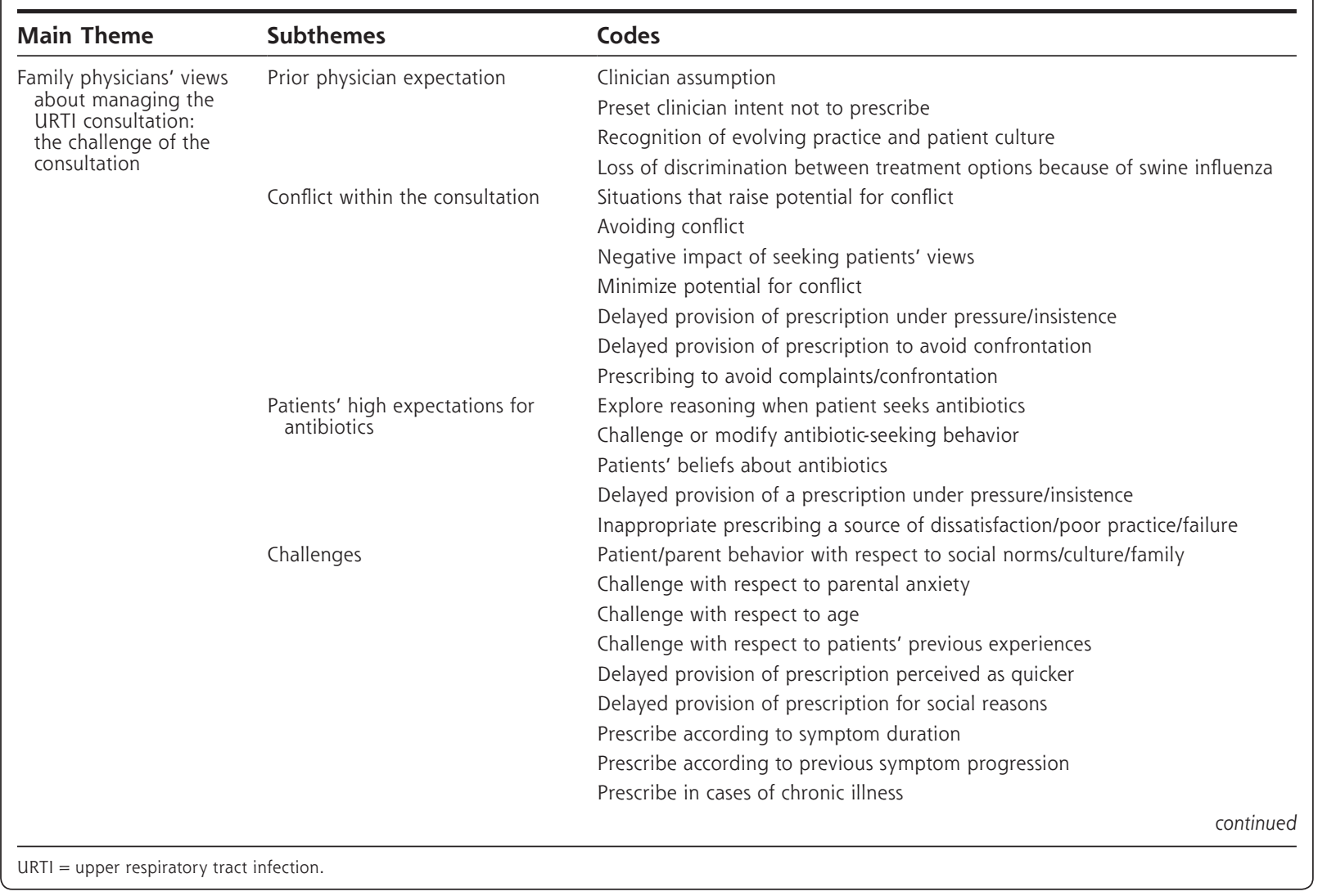


Table 2. Themes, Subthemes, and Codes Describing Family Physicians' Views and Experiences of the URTI Consultation (continued)

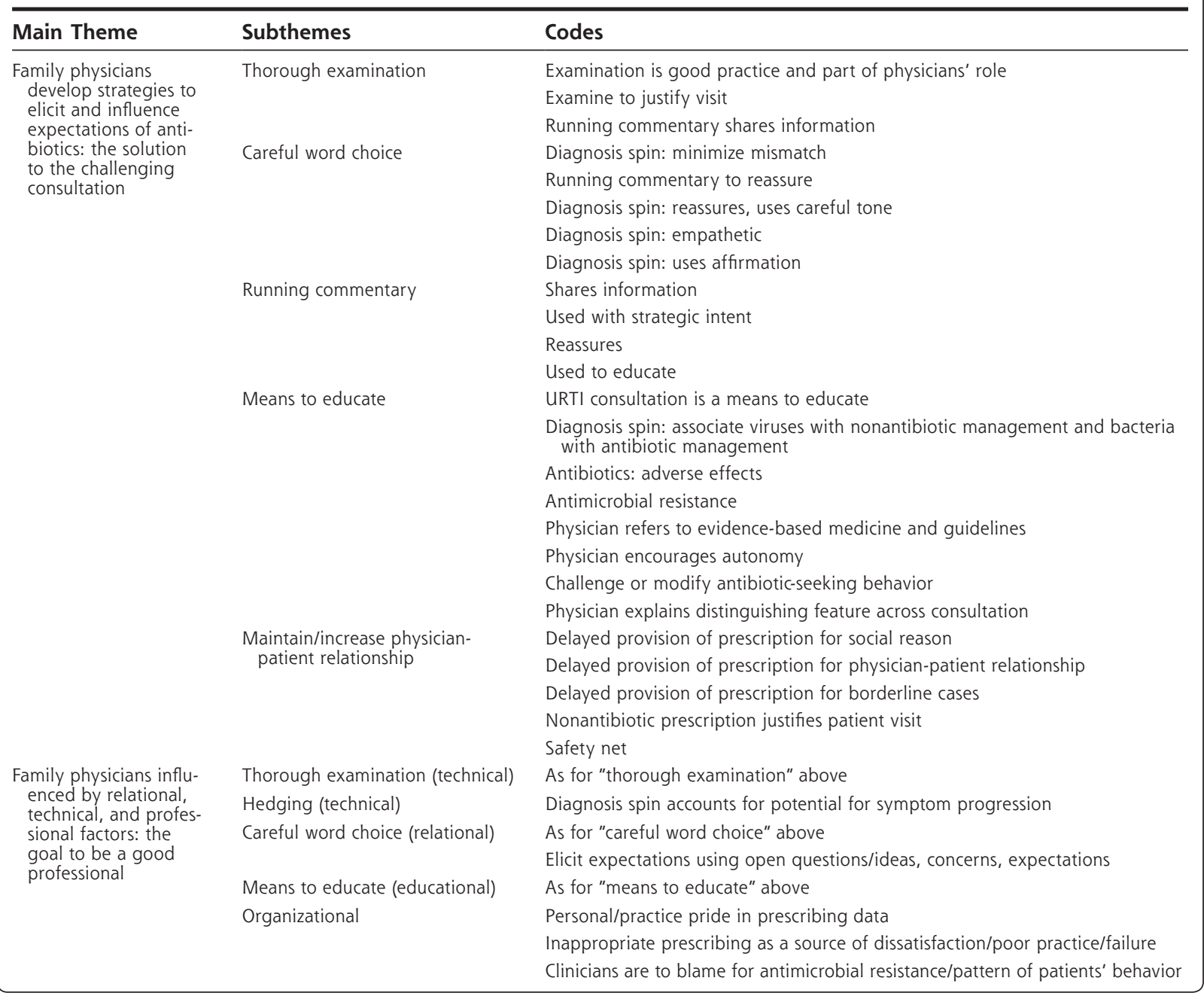

because one often perceives the expectation for antibiotics as quite high" (FP1).

The family physicians reported assuming patients wanted antibiotics, and this assumption was contrasted with their own position of preferring nonantibiotic management of viral URTIs. As one commented, "I am adamant that I don't do that with, erm, sore throats and runny noses because I feel that will take us to the practice that I had 25 years ago when you send out mixed messages to patients" (FP16). Participants reported that any mismatch between patients'
Table 3. Summary of Themes Describing Family Physicians' Views and Experiences of the URTI Consultation

\begin{tabular}{cc}
\hline Main Theme & Description, Subthemes \\
\hline $\begin{array}{c}\text { Views about managing } \\
\text { the URTI consultation }\end{array}$ & $\begin{array}{c}\text { The challenges: } \\
\text { Family physicians' preset intention not to prescribe antibiotics, } \\
\text { when feasible } \\
\text { Consultation is viewed as a source of conflict } \\
\text { Assumption that patients/parents expect to be given antibiotics } \\
\text { Family physicians' understanding of multiple, complex determi- } \\
\text { nants of patient/parent antibiotic expectation }\end{array}$ \\
$\begin{array}{c}\text { Strategies to elicit and } \\
\text { influence expecta- } \\
\text { tions of antibiotics }\end{array}$ & $\begin{array}{c}\text { Indirect elicitation of patient or parent expectation of antibiotics } \\
\text { Elicit indirectly before physical examination } \\
\text { Use physical examination and running commentary to shape } \\
\text { patient or parent expectation of antibiotics }\end{array}$ \\
$\begin{array}{c}\text { Influence of relational, } \\
\text { technical, and profes- } \\
\text { sional factors }\end{array}$ & $\begin{array}{c}\text { Preserve the physician-patient relationship } \\
\text { Prescribe appropriately }\end{array}$ \\
\hline URTI = upper respiratory tract infection.
\end{tabular}


or parents' high expectation of antibiotics and the clinician's nonprescribing approach could be problematic. As one put it, "You're not in a negotiating stand, then you are very much in a direct conflict stand, which doesn't help anyone. It certainly doesn't help you to do your job" (FP7). Consequently, the majority of family physicians who were interviewed did not directly elicit patient or parent expectation of antibiotics. Another commented, "I would never say, 'Do you want antibiotics?' because that's a recipe for disaster" (FP4). If a patient responded "yes" or "maybe" when antibiotics were not warranted, the physician would be placed in a weak negotiating position.

\section{Strategies to Elicit and Influence Expectations of Antibiotics: The Solutions}

\section{Indirectly Eliciting Expectations}

With a few exceptions, all of the family physicians expressed a preference to elicit patient or parent expectations using indirect methods. One articulated, "[My strategy] would be do my best to get them to commit themselves without me asking the direct question while I'm taking the history" (FP9). Participants explained that often patients required little prompting, as another stated: "You tend to find people have got their very fixed ideas of what they want and will actually come out I think and tell you" (FP12).

If patients or parents were not forthcoming, many physicians stated they would explore their "ideas, concerns, and expectations" (FP20) and if required, persevere with that style of communication until they were clearer about the patients' or parents' intent. As one physician put it, "I would say, 'Is there anything specific you wanted from me today?' and that then usually brings about, 'Yes,' whatever they want, and that allows me to deal with it" (FP19). The preference for this indirect method appeared to be largely rooted in the view that patients or parents often have firm expectations for receiving antibiotics. These expectations, if voiced, could prove difficult for physicians to alter, and the expectation could well become a source of disagreement if they wanted to deny antibiotics. One physician commented, "To bring it up means you got to say no. Whereas, if you don't say anything, then you might get through the whole consultation without it being confrontational" (FP13). A few participants were wary of the response indirect elicitation could provoke from the patients, however, as exemplified by this physician's words: "A lot of the time when I've said, sort of, you know, 'What are your views?' [the response has been,] 'Well, you're the one who went to medical school.' So sometimes it doesn't always work" (FP5).

One family physician did elicit directly but was selective in whom he asked: "A question that I use very often with one particular group of patients who are the chronic bronchitics, 'You know your chest better than I do; do you feel it's time for an antibiotic?"' (FP16). In contrast, a few family physicians reasoned it was entirely unnecessary to elicit expectations for antibiotics given the physician's professional role: "I don't think I need to ask an open question or a closed question saying 'Do you think that the child needs antibiotics?' That is what we are supposed to decide anyway" (FP12).

The timing of patients' or parents' expression of preference for an antibiotic shaped the remainder of the clinical encounter. One physician explained, "If things go according to plan in a consultation, you can get the patients' wishes and desires before you do the examination. So you got an idea where you stand" (FP17).

For the majority of family physicians, knowing whether the patients or parents wanted antibiotics provided the opportunity to influence their expectations. As one put it, "I've got to take into account that they think they need an antibiotic. So, look at turning it round a little bit" (FP1).

\section{Using the Physical Examination and Running Commentary}

Most family physicians used running commentary as an opportunity to modify patients' or parents' expectations once these had been discovered.

I'd do it [indirectly elicit expectations] before the physical examination because then you manipulate the findings of the physical examination. If you do it after the physical examination, you can't particularly do the manipulation around the physical examination because you don't know what their expectation is, so you don't know how to kind of package it (FP8).

Physicians used careful choice of words with strategic intent during the running commentary, as described in this comment: "I'd kind of probably put a more positive spin...instead of "You haven't got a high temperature," I'd say "That's really good, you haven't got a temperature and although your throat is really sore, it actually looks quite healthy; you know, you don't look as if you've got puss on your tonsils" (FP4).

One family physician took to using the examination to further "build a case" (FP17) by amplifying the findings. Another used a similar approach:

I do it the opposite way as well, which I know if I'm going to give an antibiotic, I will tend to exaggerate the finding, er, because that makes it easier next time when they say, "But the doctor gave me one last time." I can say, "Yes, but last time you had lots of sounds in your chest or you had a bright red throat or your tonsils looked bad, but they don't this time. Therefore there's a clear difference" (FP14). 
But patients appeared wise to such a strategy according to another family physician: "One of the tactics we do is to diminish patients' symptoms, sort of, certainly the findings if not their symptoms, but to some extent I think patients may exaggerate their symptoms as a counterstrategy" (FP8).

The family physicians also used the examination to educate patients for future illness episodes. As one explained, "If I do find a child with follicular tonsillitis, I always say to the parents, 'Come and look with me, this is what I'm looking for and if, when you see this in future, erm, you then know you need to bring them to me $^{\prime \prime \prime}(\mathrm{FP} 16)$.

\section{Influences of Relational, Technical, and Professional Factors: The Goals}

Further to avoiding potential conflict, family physicians had other strong reasons related to the physicianpatient relationship for indirectly eliciting expectations. One said, "I feel people feel affronted by that [direct elicitation of expectation], as if you're saying, 'Why have you come here, you're wasting my time'" (FP14). This desire to not appear dismissive extended into the physical examination and running commentary, as seen in this comment:

It builds the relationship during the physical examination, doesn't it, you know. What do you want for yourself? Do you want to be examined by a doctor who just kind of says, "Get up on the couch," you know, sticks the stethoscope in their ears and just silently sort of goes through the motions? Or do you want someone who's working collaboratively with you, telling you what they're finding as they're doing, you know, telling them what they're doing, reporting their findings to you and so on (FP8).

The physicians were clear what effect a good relationship can have: "The most important thing I've found in all these years of experience [is] if I have a good rapport, then I can get things done" (FP15). The family physician believed that having a good rapport helped manage expectations for antibiotics in clinical encounters wherein they were not indicated and thereby become a low prescriber of antibiotics to contain antimicrobial resistance.

Family physicians were aware of other personal and professional benefits in minimizing antimicrobial prescribing. One said, "I don't want to give them [antibiotics] because I want to be seen as a good GP [general practitioner]. I want to be seen that I'm doing the right thing by my peers" (FP7). Another narrated, "A 9-yearold said, 'Oh, that's my doctor. He doesn't believe in antibiotics.' So I felt I'd got my message across to the 9-year-old even though I hadn't got it across to the rest of the family" (FP14).

\section{DISCUSSION \\ Main Findings}

In challenging consultations where antibiotics might be expected by patients or parents, but not indicated by the clinical findings, family physicians prefer not to explore expectations in a direct manner or early on, contrary to the advice of many communication experts. Rather, clinicians prefer to use open questions and build a foundation for nonantibiotic management by using strategies to indicate their reasoning and influence expectations, such as running commentary on physical examination findings, all the while avoiding conflict and potential threats to ongoing physician-patient relationship and trust. Physical examination and commenting on findings as they emerged was therefore used to influence patient acceptance of the impending discussion about the nonantibiotic treatment strategy that the clinician had already selected.

\section{Study Strengths and Limitations}

Our study is based on data from family physicians involved in everyday clinical practice, but uptake of the invitation to participate was low, with only 20 physicians recruited.

Although the study describes reported rather than actual actions, the family physicians spoke frankly about URTI consultations and often pointed out that their practice at times ran counter to research evidence. Such revelations of why family physicians practice the way they do could not have been discerned from a survey or directly observing medical encounters. The perceptions of family physicians are important because their ideas and attitudes will determine whether they change their practice, however, the family physicians could have been motivated to present themselves favorably as being patient centered and responsible prescribers. We reassured the physicians that the purpose of the interview was not to judge their prescribing or test their knowledge of the latest guidelines, but to understand how clinicians manage the URTI consultation in real-life settings.

We may have missed important data that were obtainable from physicians who did not participate. Furthermore, it is not clear whether our findings would generalize to clinicians in other countries where the medical culture and the approach to direct elici-

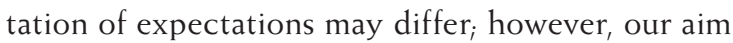
was to identify important themes from the physicians interviewed rather than generate statistically representative data.

Any decision to prescribe is made in partnership with patients. Our study design meant we did not canvass patient views 


\section{Comparison With Existing Literature}

Our findings resonate with other research that has examined how family physicians' decisions to prescribe antibiotics are influenced by a multitude of factors such as patient demand ${ }_{1}^{21-24}$ patient expectations as perceived by physicians, ${ }^{2,25-27}$ previous bad experience of nonantibiotic management, ${ }^{27}$ and influence of the physician-patient relationship. $2,28,29$

Consistent with the findings of other studies, ours suggest the main barrier to directly eliciting expectations is the potential for creating confrontation, ${ }^{2,3,30}$ with family physicians assuming patients or parents want antibiotics. ${ }^{2,3,30-34}$ Qualitative studies of audiotaped consultations for URTI symptoms cite a lack of patient centeredness as a possible explanation for clinicians overprescribing antibiotics, ${ }^{3}$ and advocate direct elicitation of expectations. ${ }^{2,5}$ In contrast to such hypothetical considerations, our study looked at the actual views of family physicians and revealed that they do not like to elicit directly because this approach could be negatively perceived, and prefer instead to ask open question to identify the concerns and expectations of patients or parents. Indeed, a study observing 36 family physician trainees in 613 consultations found that eliciting concerns, expectations, or both correlated with fewer prescriptions of medication. ${ }^{35}$

Our study found the family physicians also reported using running commentary to mold expectations and avoid antibiotic prescribing. In a crosssectional study involving 38 pediatricians in more than 500 clinical encounters of URTI symptoms, the authors concluded that inappropriate antibiotic prescribing is strongly and positively correlated with "problem" running commentary, whereby physicians conveyed the physical examination findings during the examination as being abnormal or significant. ${ }^{36}$ They speculated that avoiding this type of running commentary might avoid inappropriate prescribing in viral illness, and this approach appeared to be the case in our study as the majority of family physicians who used running commentary described using "no problem" commentary to ultimately reduce antibiotic prescribing. For example, they communicated the absence of abnormal findings (eg, "no pus on tonsils" [FP16]), minimized the importance of symptoms (eg, "throat slightly red" [FP19]), or confirmed presence of normal findings (eg, "chest clear" [FP11]).

\section{Implications for Future Research or Clinical Practice}

Interventions to promote appropriate antibiotic prescribing might include a focus on training clinicians in communication skills that promote a trusting and open physician-patient relationship, and use of running com- mentary, rather than on directly eliciting expectations as that might overlook areas of greater potential influence.

As clinicians are more likely to adhere to clinical recommendations that are compatible with their values, ${ }^{37}$ our model derived from empirical data may influence acceptance of evidence-based prescribing decisions that may be counter to patient or parent expectations. Moreover, if this goal can be accomplished within the confines of 10-minute consultations, that will enhance its acceptance and application as an intervention by family physicians who may be seeking to adopt a different approach to a challenging consultation.

The model of communication derived from our study maybe applicable for other common infections in primary care and in encounters where there is a covert patient or parent agenda.

Finally, the family physicians in our study were wary that despite indirect elicitation of expectations and running commentary, patients or parents may still not easily accept nonantibiotic management, and at that point, a few clinicians indicated that they would ultimately give a prescription of antibiotics. An alternative strategy at this juncture in the consultation may need to be explored.

To read or post commentaries in response to this article, see it online at www.annfammed.org/content/12/1/29.

Key words: antibacterial agents; health communication; physicianpatient relations; qualitative research; inappropriate prescribing; family practice; primary care; upper respiratory tract infections

Submitted August 24, 2012; submitted, revised, March 13, 2013 , accepted April 4, 2013.

Acknowledgments: We thank all the participants for their contribution to this study. We would also like to express our gratitude to Susan Evans for helping to transcribe a number of interviews and to Professor Steve Rollnick for reviewing and providing comments on the draft paper.

Guarantor: Professor Glyn Elwyn.

\section{References}

1. National Institute for Health and Clinical Excellence. Respiratory Tract Infections - Antibiotic Prescribing: Prescribing of Antibiotics for Self-Limiting Respiratory Tract Infections in Adults and Children in Primary Care. Clinical Guideline No. 69. London, UK: NICE; 2008.

2. Butler CC, Rollnick S, Pill R, Maggs-Rapport F, Stott N. Understanding the culture of prescribing: qualitative study of general practitioners' and patients' perceptions of antibiotics for sore throats. BMJ. 1998;317(7159):637-642.

3. Altiner A, Knauf A, Moebes J, Sielk M, Wilm S. Acute cough: a qualitative analysis of how GPs manage the consultation when patients explicitly or implicitly expect antibiotic prescriptions. Fam Pract. 2004;21(5):500-506.

4. Altiner A, Brockmann S, Sielk M, Wilm S, Wegscheider K, Abholz $\mathrm{HH}$. Reducing antibiotic prescriptions for acute cough by motivating GPs to change their attitudes to communication and empowering patients: a cluster-randomized intervention study. J Antimicrob Chemother. 2007;60(3):638-644. 
5. Rollnick S, Seale C, Rees M, Butler C, Kinnersley P, Anderson L. Inside the routine general practice consultation: an observational study of consultations for sore throats. Fam Pract. 2001;18(5): 506-510.

6. Coenen S, Michiels B, Van Royen P, Van der Auwera JC, Denekens J. Antibiotics for coughing in general practice: a questionnaire study to quantify and condense the reasons for prescribing. BMC Fam Pract. 2002;3:16.

7. Cockburn J, Pit S. Prescribing behaviour in clinical practice: patients' expectations and doctors' perceptions of patients' expectations-a questionnaire study. BMJ. 1997;315(7107):520-523.

8. Britten N, Stevenson FA, Barry CA, Barber N, Bradley CP. Misunderstandings in prescribing decisions in general practice: qualitative study. BMJ. 2000;320(7233):484-488.

9. Francis NA, Butler CC, Hood K, Simpson S, Wood F, Nuttall J. Effect of using an interactive booklet about childhood respiratory tract infections in primary care consultations on reconsulting and antibiotic prescribing: a cluster randomised controlled trial. BMJ. 2009. 339:b2885

10. Butler CC, Simpson SA, Dunstan F, et al. Effectiveness of multifaceted educational programme to reduce antibiotic dispensing in primary care: practice based randomised controlled trial. BMJ. 2012;344:d8173.

11. Cals JWLL, Scheppers NA, Hopstaken RM, et al. Evidence based management of acute bronchitis; sustained competence of enhanced communication skills acquisition in general practice. Patient Educ Couns. 2007;68(3):270-278.

12. Briel M, Langewitz W, Tschudi P, Young J, Hugenschmidt C, Bucher HC. Communication training and antibiotic use in acute respiratory tract infections. A cluster randomised controlled trial in general practice. Swiss Med W/kly. 2006;136(15-16):241-247.

13. Arnold SR, Straus SE. Interventions to improve antibiotic prescribing practices in ambulatory care. Cochrane Database Syst Rev. 2005; (4):CD003539.

14. Coenen S, Van Royen P, Michiels B, Denekens J. Optimizing antibiotic prescribing for acute cough in general practice: a cluster-randomized controlled trial. J Antimicrob Chemother. 2004;54(3):661-672.

15. Welschen I, Kuyvenhoven MM, Hoes AW, Verheij TJ. Effectiveness of a multiple intervention to reduce antibiotic prescribing for respiratory tract symptoms in primary care: randomised controlled trial. BMJ. 2004;329(7463):431-435.

16. Gonzales R, Steiner JF, Lum A, Barrett PH Jr. Decreasing antibiotic use in ambulatory practice: impact of a multidimensional intervention on the treatment of uncomplicated acute bronchitis in adults. JAMA. 1999;281(16):1512-1519.

17. Stivers T. Prescribing Under Pressure. Oxford, United Kingdom: Oxford University Press; 2007.

18. Légaré $F$, Labrecque $M$, Leblanc $A$, et al. Does training family physicians in shared decision making promote optimal use of antibiotics for acute respiratory infections? Study protocol of a pilot clustered randomised controlled trial. BMC Fam Pract. 2007;8:65.

19. Bloor M. Addressing social problems through qualitative research. In: Silverman D, ed. Qualitative Research: Theory, Method and Practice. London, United Kingdom: Sage Publications; 1997.

20. Green J, Thorogood N. Qualitative Methods for Health Research. London, United Kingdom: Sage Publications; 2004.

21. Fischer $T$, Fischer $S$, Kochen MM, Hummers-Pradier E. Influence of patient symptoms and physical findings on general practitioners' treatment of respiratory tract infections: a direct observation study. BMC Fam Pract. 2005;6(1):6.
22. Mangione-Smith R, McGlynn EA, Elliott MN, McDonald L, Franz CE, Kravitz RL. Parent expectations for antibiotics, physicianparent communication, and satisfaction. Arch Pediatr Adolesc Med. 2001;155(7):800-806.

23. Scott JG, Cohen D, DiCicco-Bloom B, Orzano AJ, Jaén CR, Crabtree $\mathrm{BF}$. Antibiotic use in acute respiratory infections and the ways patients pressure physicians for a prescription. J Fam Pract. 2001;50(10):853-858.

24. Vazquez-Lago JM, Lopez-Vazquez P, López-Durán A, Taracido-Trunk $M$, Figueiras A. Attitudes of primary care physicians to the prescribing of antibiotics and antimicrobial resistance: a qualitative study from Spain. Fam Pract. 2012;29(3):352-360.

25. Coenen S, Van Royen P, Vermeire E, Hermann I, Denekens J. Antibiotics for coughing in general practice: a qualitative decision analysis. Fam Pract. 2000;17(5):380-385.

26. Lopez-Vazquez P, Vazquez-Lago JM, Figueiras A, Figueiras A. Misprescription of antibiotics in primary care: a critical systematic review of its determinants. J Eval Clin Pract. 2012;18(2):473-484.

27. Kumar S, Little P, Britten N. Why do general practitioners prescribe antibiotics for sore throat? Grounded theory interview study. BMJ. 2003;326(7381):138-143.

28. Petursson P. GPs' reasons for "non-pharmacological" prescribing of antibiotics. A phenomenological study. Scand J Prim Health Care. 2005;23(2):120-125.

29. Hart AM, Pepper GA, Gonzales R. Balancing acts: deciding for or against antibiotics in acute respiratory infections. J Fam Pract. 2006;55(4):320-325.

30. Britten N. Patients' expectations of consultations. BMJ. 2004;328 (7437):416-417.

31. Macfarlane J, Holmes W, Macfarlane R, Britten N. Influence of patients' expectations on antibiotic management of acute lower respiratory tract illness in general practice: questionnaire study. BMJ. 1997;315(7117):1211-1214.

32. Britten $N$, Ukoumunne $\mathrm{O}$. The influence of patients' hopes of receiving a prescription on doctors' perceptions and the decision to prescribe: a questionnaire survey [see comments]. BM]. 1997;315(7121):1506-1510.

33. Mangione-Smith R, McGlynn EA, Elliott MN, Krogstad P, Brook $\mathrm{RH}$. The relationship between perceived parental expectations and pediatrician antimicrobial prescribing behavior. Pediatrics. 1999;103(4 Pt 1):711-718.

34. Stivers T, Mangione-Smith R, Elliott MN, McDonald L, Heritage J. Why do physicians think parents expect antibiotics? What parents report vs what physicians believe. J Fam Pract. 2003;52(2):140-148.

35. Matthys J, Elwyn G, Van Nuland M, et al. Patients' ideas, concerns, and expectations (ICE) in general practice: impact on prescribing. Br J Gen Pract. 2009;59(558):29-36.

36. Heritage J, Elliott MN, Stivers T, Richardson A, Mangione-Smith R. Reducing inappropriate antibiotics prescribing: the role of online commentary on physical examination findings. Patient Educ Couns. 2010;81(1):119-125

37. Tonkin-Crine S, Yardley L, Little P. Antibiotic prescribing for acute respiratory tract infections in primary care: a systematic review and meta-ethnography. J Antimicrob Chemother. 2011;66(10):2215-2223. 